\title{
The new agreement of the international RIGA consensus conference on nasal airway function tests*
}

\author{
Klaus Vogt ${ }^{1}$, Gregor Bachmann-Harildstad², Andreas Lintermann ${ }^{3,4}$, Alina \\ Nechyporenko ${ }^{5}$, Franz Peters ${ }^{6}$, Klaus-Dieter Wernecke ${ }^{7}$ \\ Rhinology 56; 2: 133-143, 2018 \\ https://doi.org/10.4193/Rhin17.084 \\ ' University of Latvia, Center of Experimental Surgery, Riga, Latvia \\ *Received for publication: \\ 2 Department of otorhinolaryngology, Akershus University Hospital and Institute of Clinical Medicine, Akershus University Hospital, April 28, 2017 \\ Oslo University, Lørenskog, Norway \\ Accepted: November 23, 2017 \\ ${ }^{3}$ Institute of Aerodynamics and Chair of Fluid Mechanics, RWTH Aachen University, Aachen, Germany \\ ${ }^{4}$ Jülich Aachen Research Alliance, High Performance Computing (JARA-HPC), RWTH Aachen University, Aachen, Germany \\ ${ }^{5}$ Kharkiv National University of Radio Electronics, Department of Biomedical Engineering, Kharkiv, Ukraine \\ ${ }^{6}$ Ruhr-Universität Bochum, Mechanical Engineering, Fluid Mechanics, Bochum, Germany \\ ${ }^{7}$ Charité- Universitätsmedizin Berlin, Berlin, Germany
}

\begin{abstract}
The report reflects an agreement based on the consensus conference of the International Standardization Committee on the Objective Assessment of the Nasal Airway in Riga, 2nd Nov. 2016.

The aim of the conference was to address the existing nasal airway function tests and to take into account physical, mathematical and technical correctness as a base of international standardization as well as the requirements of the Council Directive 93/42/EEC of 14 June 1993 concerning medical devices.

Rhinomanometry, acoustic rhinometry, peak nasal inspiratory flow, Odiosoft-Rhino, optical rhinometry, 24-h measurements, computational fluid dynamics, nasometry and the mirrow test were evaluated for important diagnostic criteria, which are the precision of the equipment including calibration and the software applied; validity with sensitivity, specificity, positive and negative predictive values, reliability with intra-individual and inter-individual reproducibility and responsiveness in clinical studies. For rhinomanometry, the logarithmic effective resistance was set as the parameter of high diagnostic relevance. In acoustic rhinometry, the area of interest for the minimal cross-sectional area will need further standardization. Peak nasal inspiratory flow is a reproducible and fast test, which showed a high range of mean values in different studies. The state of the art with computational fluid dynamics for the simulation of the airway still depends on high performance computing hardware and will - after standardization of the software and both the software and hardware for imaging protocols - certainly deliver a better understanding of the nasal airway flux.
\end{abstract}

Key words: nasal cavity, nasal mucosa, nasal septum, physiology, diagnosis

\footnotetext{
Abbreviations and symbols

AAR: active anterior rhinomanometry; AR: acoustic rhinometry; BCE: before the Common Era; CFD: computational fluid dynamics; COSMIN: Consensus-based Standards for the selection of health Measurement Instruments; EEG: electro-encephalogram; FSO: full signal output; FEV1: forced expiratory volume during the first second; GBI: Glasgow Benefit Inventory; GHSI: Glasgow Health Status Inventory; h: hour; Hz: Hertz; ISCOANA: International Standardization Committee on the Objective Assessment of the Nasal Airway; LBM: Lattice-Boltzmann methods; Ig: logarithm; mCSA: minimal cross-sectional area; NCV: nasal cavity volume; NOSE: nasal obstruction symptom evaluation score; OR: Odiosoft-rhino; Pa: Pascal; PEF: peak expiratory flow; PNIF: peak nasal inspiratory flow; RANS: Reynolds-averaging Navier-Stokes approach; Reff: effective resistance; ReffEx: effective resistance during exhalation; Reffln: effective resistance during inhalation; REM: rapid eye movements; RANS: Reynolds-averaged NavierStokes approach; $\dot{V}$ : volume flux; $\triangle \mathrm{P}$ : pressure difference; $4 \mathrm{PR}$ : Four-phases rhinomanometry
} 


\section{Introduction}

The consensus conference dealt with the validity of objective measurements of the nasal airway. Participants included members of the International Standardization Committee on the Objective Assessment of the Nasal Airway (ISCOANA) and experts from Austria, Germany, Greece, Italy, Norway, Latvia and Ukraine, representing physics, mathematics, statistics, fluid dynamics, biotechnology and clinical rhinology. The consensus conference to update nasal function tests was necessary because some of the diagnostic procedures currently in use in rhinology no longer fulfil the requirements of quality management for medical devices. In addition, recent studies critically evaluating techniques for nasal airway assessment have not addressed technical progress in this field in recent years and the resulting experimental work, which has a great impact on daily practice (1). The experiments of Wong and Eccles are not fully representative, because the artificial resistance units did not resemble the elasticity of the human nose, which includes skin, cartilage, connective tissue, mucosa and mucociliary epithelia. The elasticity of the nasal vestibule and the nasal cavity has an impact on nasal obstruction in all four different breathing phases ${ }^{(2)}$. All medical devices must comply with regulations concerning general stateof-the-art techniques and information technology. Furthermore, nasal airway function tests should be used with consideration of the extensive information obtained by means of computational fluid dynamics (CFD) methods, which is the most important upcoming method for the detailed topical analysis of the airflow in selected regions of interest in the upper airway. However, the basis of every nasal airway assessment is the synthesis of anamnesis, anterior rhinoscopy, endoscopic anterior rhinoscopy, endoscopy and posterior rhinoscopy or transnasal flexible endoscopy of the epipharynx.

It was necessary to achieve an agreement on the accuracy of rhinomanometric measurements in the first part of the conference and, in the second part, to consider the strength of evidence and measuring conditions of other methods such as acoustic rhinometry (AR), peak nasal inspiratory flow (PNIF), optical rhinometry, mirror test and $24 \mathrm{~h}$-measurements as tools in practice and research. The experience of nasal obstruction is one of the most common issues in rhinology as summarised recently in an editorial ${ }^{(3)}$.

\section{Part I: Update on standard recommendations for rhinomanometry}

Moderator: Klaus Vogt

Speakers: Klaus Vogt/Germany and Latvia; Alina Nechyporenko/ Ukraine, Franz Peters/Germany; Andreas Lintermann/Germany

\section{Updated Standard for Rhinomanometry 2016 (Riga}

Standard)

In the systematic discussion of the previous standard for rhinomanometry, three issues were presented in detail because of their relationship to accurate measurements or evaluation with rhinomanometry: first, information on loops in the pressure-volume flow diagram of rhinomanometry obtained with extended model experiments ${ }^{(4)}$; secondly, the relationship between CFD and rhinomanometry ${ }^{(5)}$; and thirdly, the derivation of the hydrodynamic resistance coefficient ${ }^{(6,7)}$.

The standard recommendations determined during this meeting are an update to the 1984 recommendations of the ISCOANA (8) and the 2005 "Consensus report on acoustic rhinometry and rhinomanometry", including the addendum to that report ${ }^{(9)}$. The recommendations concern active anterior rhinomanometry (AAR) and active posterior rhinomanometry (APR) with the restrictions for APR outlined below.

A. Specifications for flow and pressure measurement channels.

The flow and pressure measurement channels should provide linearity within a range of $+/-1200 \mathrm{~cm}^{3} / \mathrm{s}$ for flow and $1200 \mathrm{~Pa}$ for differential pressure. The response time for both channels shall provide a reliable measurement up to $80 \mathrm{~Hz}$ with a maximal error of $2 \%$ of the FSO. The temperature and humidity ranges that allow accurate measurement should be specified. If mass flow meters are used for flow measurements, the software must allow for adjustment of the flow channel according to the altitude above sea level.

Comment: Mass flow meters, used in anaesthesiology and intensive care, are highly accurate and sensitive sensors designed to measure breathing. They do not require the tubal connections necessary in pneumotachography. Because the density of air depends on the environmental pressure, mass flow meters must be adjusted according to altitude above sea level.

\section{B. Calibration intervals.}

The first calibration of the rhinomanometer must be carried out by the producer. Recalibration intervals must be specified in the user's manual.

Comment: The recalibration interval depends primarily on the type of sensor. While modern solid-state sensors do not need recalibration except after unexpected events, repair or changes in location (altitude above level sea), older devices do need calibration control at fixed intervals. Rhinomanometer calibration must be documented before and after studies as well as when rhinomanometer use has a medico-legal impact. Therefore, a simple calibration control device should be included with the necessary accessories. 


\section{Fixation of the pressure tube.}

Fixation of the pressure tube should not affect the shape of the nasal entrance and should not restrict its motility during measurement. Therefore, adhesive tape remains the standard for fixation. Other types of connection should be checked against tape fixation ${ }^{(8,9)}$. The tightness of the tape must be checked prior to measurement by closing the contralateral nostril with a lateral finger press, by blocking the silicone pressure tube, and by asking the patient to close the lips and to both inhale and exhale. Rarely, it is impossible to fix the pressure tube in an air-tight manner. In this case, fatty skin or make-up has to be cleaned and/or a few millimetre of the moustache or beard has to be shaved next to the nostrils.

Comment: This recommendation from 1984 remains very important and determines the initial accuracy of rhinomanometric measurements. However, producers of rhinomanometers and accessories sell nasal olives or sponge devices, which are popular among medical assistants because of their ease of use. Nasal olives and other sealing devices not only distort the closed nostril but also alter the contralateral airflow. This distortion exceeds by far the effects of decongestants or allergens. Thus, the results obtained are inaccurate and useless for functional diagnostics.

\section{Mask.}

The mask must be transparent, to allow visualization of oral tightness, must be clean according to hygienic standards, and must be adaptable to a bacterial filter to minimize the risk of contamination. The mask must fit the patient's face without disturbing the functional anatomy of the anterior nose.

Comment: Generally, full-face masks (respiratory protective masks) or anaesthesiology masks can be used. The investigator must evaluate possible distortion of the midface, especially in the case of children. Racial differences must be considered. When using full-face masks, the dead-space or mask volume is higher. This extra volume may influence measurements if the resistance of the device including the bacterial filter is high.

\section{E. Measurement conditions.}

Ingestion of alcoholic beverages is not allowed $16 \mathrm{~h}$ prior to measurement. This applies to all objective measurements. When in doubt, a blood sample must be taken to verify that the alcohol level is below $0.1 \mathrm{mg} / \mathrm{g}$ (alternative $0.1 \%$ o) ${ }^{(10)}$. All objective measurements must be made under standardized indoor measurement conditions. The indoor temperature must be between 18 and 35 degrees Celsius and the humidity must be at least $30 \%$. The period of adaptation depends on the ratio between outdoor and indoor temperature. A minimum time period of 10 min is recommended for acclimatization to indoor room temperature and humidity in the waiting room. The patient should be

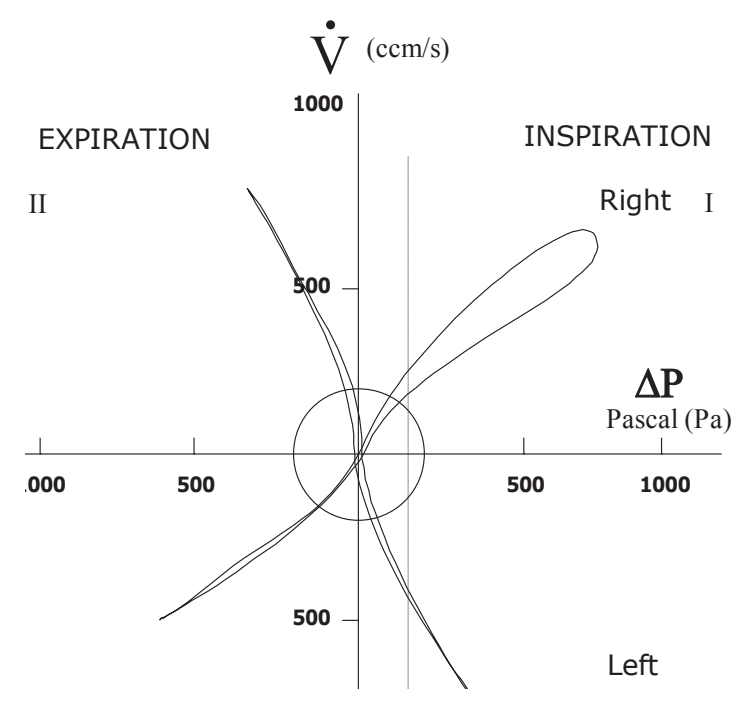

Figure 1. Graph of rhinomanometric measurements. Pressure difference of $150 \mathrm{~Pa}$ indicated by light gray line. (Figure from Rhinology Supplement 21).

seated comfortably during recording.

Comment: Reference data ("normal" values, classifications of obstruction) should be obtained under these conditions ${ }^{(11-13)}$. Physical effort rapidly diminishes nasal resistance. Airway resistance is markedly elevated in the supine position. Nasal resistance is lower during growth; the influence of age between 6 and 15 years can be estimated by correlation with anthropometric data.

\section{F. Graphical information.}

The relationship between pressure difference $\Delta \mathrm{P}$ and volume flux $\dot{V}$ is depicted in Figure 1 (Consensus report 2005, Figure 36). The lengths of the $x$-axis and $y$-axis must provide all information in the physiological range of $1000 \mathrm{~cm}^{3} / \mathrm{s}$ and $1000 \mathrm{~Pa}$. "Radius 2" as part of the polar coordinate system of Broms can be depicted as additional information ${ }^{(14)}$. The flow at 150 Pa can be indicated by a dashed line. A proportional dynamic extension of the range can be implemented, if the standard range does not depict the full range of the actual measurement.

To better understand time-dependent changes and to identify measurement errors separately for each measurement channel, it is useful to add an additional graph depicting the timeline of flux and pressure difference (Figure 2).

Comment: Nearly all modern rhinomanometers depict more or less expressed loops instead of a simple bent line. Loops as technical errors are excluded in rhinomanometers with short response times as defined above. The physical background of loops has been extensively described in model experiments with numerical calculations ${ }^{(4)}$. Asymmetric loops provide important additional visual information indicating the influence of elastic compartments such as the nasal valve and the soft palate (Starling resistor). 


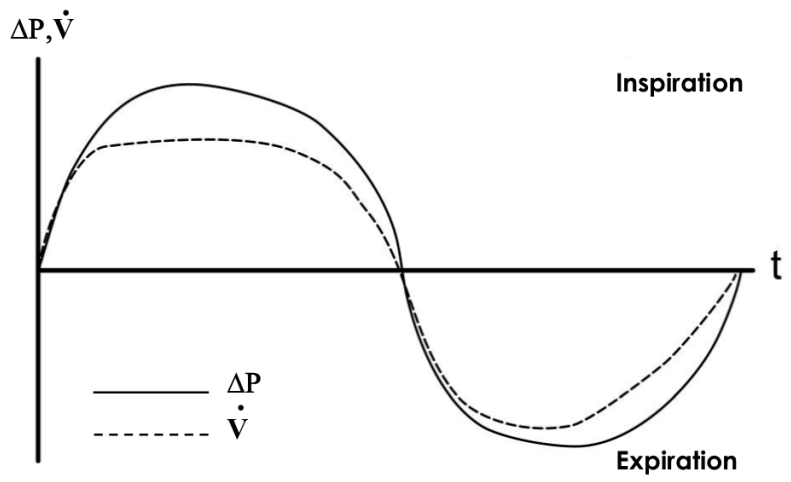

Figure 2. Timeline of pressure difference $\Delta \mathrm{P}$ and volume flux $\dot{V}$

If the rhinomanometric graph does not show loops at all, the software is not in agreement with the basic norm of software in medical products (ISO 14971, IEC 62304) because the averaging procedure is erroneous.

The physical units agree with the SI system and the Council Directive 89/617 of the European Union.

The additional graphs of the timelines of volume flux and pressure difference provide information about correct measurements of both channels or errors resulting from these measurements and contribute to a better understanding of loops caused by elastic compartments of the nasal channel. "Flow limitations", as described in sleep medicine, are better visualized in the two-channel timeline.

\section{G. Numerical information.}

The basic numerical information shall be the effective resistance of the entire breath (Reff) and the effective resistance during inspiration (Reffln) and expiration (ReffEx). For clinical purposes the values shall be expressed as common logarithmic values LReff, LReffIn and LReffEx, where LReff $=\lg$ (Reff), LReffln = lg (Reffln) and LReffEx = Ig (ReffEx). For easier practical use, clinical data should be given as LReff $=\lg (10$ Reff $)$, LReffin $=\lg (10$ Reffln $)$ etc.

Derivation of effective resistance:

Effective resistance is an important term in electricity, where voltage is generally measured as "effective voltage", which is the root mean square (RMS) of voltage. In rhinomanometry effective resistance is calculated as

$$
W_{e f f}=\sqrt{\frac{1}{T} \int_{0}^{T} w^{2} d t}
$$

where $\mathrm{w}$ is the value $\Delta \mathrm{P}$ or $\dot{V}$

$$
R_{e f f}=\frac{\Delta P_{e f f}}{V_{e f f}}\lfloor P a s / \mathrm{ccm}\rfloor
$$

where $\Delta \mathrm{P}_{\text {eff }}$ and $\dot{V}_{\text {eff }}$ are the effective pressure loss and volume flux over the complete respiratory cycle.
Comments: As described in the standard recommendation of 1984, the calculation of resistance at $150 \mathrm{~Pa}$ is not correct, because this point of a breathing curve is in the accelerating or decelerating region of the curve, where the pressure/volume flux relationship is nonlinear. The resistance differs and depends on the pressure at any point of the breathing wave. Furthermore, a pressure of $150 \mathrm{~Pa}$ is frequently not reached in normal unstrained breathing cycles. With state-of-the-art sensor techniques and information technology it is not necessary to use estimations, because exact measurement results can be used as the basis for diagnostic parameters. Applying resistance at $150 \mathrm{~Pa}$ or replacing this value with resistance at another point (75 Pa for example) leads to erroneous results and is not in agreement with the normative conditions mentioned above. In summary, the nasal resistance in classical AAR is calculated on one single volume value at one fixed pressure at $150 \mathrm{~Pa}$ (alternative $75 \mathrm{~Pa}$ ) whereas the nasal resistance in $4 P R$ is calculated on the area under the curve of hundreds of resistances continuously recorded during inspiration and expiration along the entire breathing cycle. Effective resistance is closely related to "surface under tracing" as described by Naito et al. ${ }^{(15)}$.

Many studies have shown that rhinomanometric one-point measurements and linear effective resistance are only weakly or not at all correlated with the feeling of nasal obstruction(16). Extended contradictory clinical studies have shown that according to the Weber-Fechner law the logarithmic effective resistance and logarithmic vertex resistance correlate significantly with subjective scores as measured on a visual analogue scale ${ }^{(11,16)}$.

Based on 36,500 active anterior rhinomanometry measurements and 10,030 measurements of calculated total resistance, a clinical classification for nasal obstruction in increments of $20 \%$ is now available for Caucasian noses (Table 1).

Additional numerical parameters:

Additional parameters can be included in the rhinomanometer software, if the derivation or algorithms of the parameters are published and reproducible by anyone on demand. The clinical meaning and relevance of new parameters must be validated in clinical studies. The parameters listed in Table 2 are presently in use.

\section{Comments:}

1. The flow at $150 \mathrm{~Pa}$ should remain available to allow comparison of new measurement results with the results of older rhinomanometers. The flow sum of both sides at $150 \mathrm{~Pa}$ and the side quotient (lateralization percentage) are correct parameters for the evaluation of total nasal airflow (17).

2. The calculation of total nasal resistance with the equation for parallel electric resistors is estimated, because of the unknown role of the nasopharynx. However, this calculation is more reliable than the measurements of posterior rhinomanometry because that method is limited by the cooperation of the 
Table 1. Classification of nasal obstruction according to active anterior rhinomanometry in 36,500 measurements.

\begin{tabular}{|cccccc|}
\hline & & \multicolumn{2}{c}{ Unilateral Resistance } & \multicolumn{2}{c|}{ Total Resistance } \\
\hline Class & & Untreated & $\begin{array}{c}\text { after de- } \\
\text { congestion }\end{array}$ & Untreated & $\begin{array}{c}\text { after de- } \\
\text { congestion }\end{array}$ \\
\hline $\mathbf{1}$ & $0-19 \%$ & $<0.71$ & $<0.63$ & $<=0.42$ & $<=0.36$ \\
\hline $\mathbf{2}$ & $20-39 \%$ & $0.71-0.89$ & $0.63-0.78$ & $0.42-0.57$ & $0.36-0.47$ \\
\hline $\mathbf{3}$ & $40-59 \%$ & $0.89-1.08$ & $0.78-0.94$ & $0.57-0.70$ & $0.48-0.59$ \\
\hline $\mathbf{4}$ & $60-79 \%$ & $1.09-1.35$ & $0.94-1.18$ & $0.70-0.90$ & $0.59-0.76$ \\
\hline $\mathbf{5}$ & $80-100 \%$ & $>1.35$ & $>1.18$ & $>0.90$ & $>0.76$ \\
\hline
\end{tabular}

The classification is valid for LReff, LReffin, LReffex, LVRin, LVRex, where LReff $=\lg 10$ Reff etc. Class 1 represents noses without any obstruction while class 5 corresponds to total functional blockage ${ }^{(12)}$.

patient.

3. Vertex resistance and logarithmic vertex resistance. The vertex resistance is defined as the resistance measured at the highest point of the flow curve during quiet breathing. This part of the curve is characterized by a steady airflow and is important for further correlations with CFD. Vertex resistance and effective resistance in normal breathing are statistically strongly correlated. They differ in inspiration in case of the onset of nasal valve activity. Vertex resistance and peak flow resistance have been confirmed as reliable parameters in early studies of rhinomanometry ${ }^{(14)}$. Neither vertex resistance nor peak flow resistance in rhinomanometry is related to or comparable with PNIF.

4. The hydrodynamic resistance coefficient may be considered as a new classification of nasal obstruction, independent of racial differences in nasal shape, for the investigation of different nasal activities (calm breathing, breathing during physical exertion, influence of nasal cycle) $)^{(6,18)}$. The hydrodynamic resistance coefficient is a dimensionless coefficient, which takes into account laminar and turbulent regimes of flow. Hydrodynamic resistance coefficient and vertex resistance are highly correlated.

5. With resistometry both resistance and hydraulic diameter were shown to distinguish healthy from rhinologic patients in a prospective cohort study. Reference values were determined and published ${ }^{(19)}$. The clinical value of this information has been demonstrated in a prospective case series with a 1-year follow-up ${ }^{(20,21)}$. The calculation of linear resistance at 250 $\mathrm{cm}^{3} / \mathrm{s}$ is physically incorrect because there is no linear relationship between pressure and volume flux at this point.

6. Calculation of breathing performance as $\triangle P \dot{V}$ and the calculation of breathing work may provide additional physiological information ${ }^{(22)}$. The clinical impact of this information is limited because performance and work depend on the depth of a breath ${ }^{(57)}$.

\section{Part II: Diagnostic strength of nasal airway function tests}

Moderator: Gregor Bachmann-Harildstad/Norway

Speakers: Klaus-Dieter Wernecke/Germany; Mara Argale, Krista Kaulina, Rudolf Viksne/Latvia; E.G. Wuestenberg/Germany; Gregor Bachmann-Harildstad/Norway; Klaus Vogt/Latvia and Germany

In an introductory lecture Klaus-Dieter Wernecke summarised the importance of applying the criteria for evidence-based medicine to critically evaluate the diagnostic power of current diagnostic methods. Within this context it is necessary to determine the validity of information obtained with each method and the application of this information to clinical problems and decisionmaking related to the care of individual patients.

The criteria for diagnostic power are:

- Reproducibility (reliability) and responsiveness under physiological and pathophysiolgical conditions (reliability refers to both interrater agreement as to whether the criteria that define a disorder occur in a patient population, and to the consistency with which any particular diagnosis is made over time)

- Diagnostic validity as measured by sensitivity, specificity, positive and negative predictive values as well as overall accuracy (validity refers to the accuracy with which the mentioned criteria define and differentiate a disease from other diseases)

- These definitions include in particular:

- Precision and accuracy of measurements as given by technical equipment and/or software details (evaluating gauge repeatability and reproducibility)

- Intra-individual variability

- Inter-individual variability

- Arguable agreement with other methods of measuring

- Comparability under different clinical conditions Appropriate statistical procedures for evaluation with these criteria have been shown in the examples.

\section{1) Active anterior rhinomanometry (AAR).}

The topic was extensively discussed in the first session. Increased diagnostic power has been achieved in recent years with the analysis of comprehensive clinical data after correction of obsolete calculations and the introduction of new parameters (4PR). A classification of obstruction in Caucasian noses is available; corrections for noses during growth will be published soon. By choosing correct parameters, a direct relation to CFD measu- 
Table 2. Additional parameters in rhinomanometry.

\begin{tabular}{|c|c|c|c|c|}
\hline Parameter & Author & Calculation & Additional information & Validation \\
\hline Flow at $150 \mathrm{~Pa}$ & ISOANA $^{8,9}$ & & Comparison with references & Yes \\
\hline Flow sum at $150 \mathrm{~Pa}$ & ISOANA ${ }^{8,9}$ & $\dot{V}_{\text {right }}+\dot{V}_{\text {left }}$ & Total nasal airflow & Yes \\
\hline $\begin{array}{l}\text { Lateralization } \\
\text { percentage }\end{array}$ & $\begin{array}{l}\text { Postema et } \\
\text { al. }{ }^{17}\end{array}$ & $\dot{V}_{\text {right }} / \dot{V}_{\text {left }}$ & Lateralization & Yes \\
\hline $\begin{array}{l}\text { Calculated total } \\
\text { resistance }\end{array}$ & ISOANA ${ }^{8,9}$ & $\begin{aligned} & R_{\text {Tot }}=R_{\text {right }} * R_{\text {left }} /\left(R_{\text {right }}+R_{\text {left }}\right) \\
& \text { for } \mathrm{R}=\text { Reff, LReff, ReffIn, LReffln, ReffEx, LReffEx }\end{aligned}$ & Total nasal resistance & Yes \\
\hline $\begin{array}{l}\text { Nasal breathing } \\
\text { performance }\end{array}$ & Eichler 22 & $P_{N}=\Delta P \dot{V}$ & Alternative parameter & No \\
\hline Polynomial model & Rohrer & $\begin{array}{c}\Delta P=k_{1} \dot{V}+k_{2} \dot{V}^{2} \\
\text { where } \mathrm{k}_{1}=\text { linear coefficient, } \mathrm{k}_{2}=\text { quadratic coefficient }\end{array}$ & Curve adaption & No \\
\hline $\begin{array}{l}\text { Vertex resistance } \\
\text { (VR), Logarithmic } \\
\text { Vertex Resistance } \\
\text { (LVR) }\end{array}$ & Vogt et al. ${ }^{11}$ & $\Delta P / \dot{V}$ at maximum flow (inspiration, expiration) & $\begin{array}{l}\text { Resistance at steady flow (inspira- } \\
\text { tion, expiration) }\end{array}$ & Yes \\
\hline Radius 2 & Broms ${ }^{14}$ & Angle in a polar coordinate system for pressure and flow & Comparative parameter & Yes \\
\hline $\begin{array}{l}\text { Hydrodynamic re- } \\
\text { sistance coefficient } \\
\text { (HRC) }\end{array}$ & $\begin{array}{l}\text { Garyuk, Nec- } \\
\text { hyporenko }\end{array}$ & 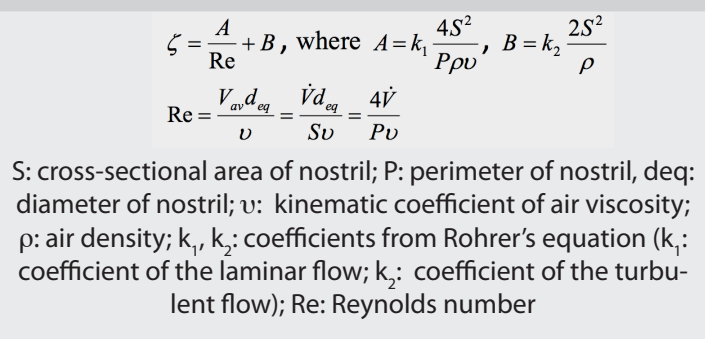 & New classification possible & No \\
\hline $\begin{array}{l}\text { Resistance in resis- } \\
\text { tometry }\end{array}$ & $\begin{array}{l}\text { Mlynski, } \\
\text { Löw }^{19}\end{array}$ & $\mathrm{R}=\Delta \mathrm{P} / \dot{V}$ at $250 \mathrm{ml} / \mathrm{s}$ & Comparison with references & Yes \\
\hline Hydraulic diameter & $\begin{array}{l}\text { Mlynski, } \\
\text { Löw }^{19}\end{array}$ & $\begin{aligned} d_{h} & =2 \sqrt[4]{\frac{8 \dot{V} \eta l}{\Delta P \pi}} \\
\eta=\text { viscosity }, I & =\text { length of nasal cavity }\end{aligned}$ & $\begin{array}{l}\text { Measure for the width of the } \\
\text { nasal flow channel during laminar } \\
\text { flow }\end{array}$ & Yes \\
\hline $\begin{array}{l}\text { Flow at beginning } \\
\text { of nasal valve col- } \\
\text { lapse }\end{array}$ & $\begin{array}{l}\text { Beule, } \\
\text { Mlynski, Gog- } \\
\text { niashwili }^{20}\end{array}$ & Difference between calculated $\mathrm{R}$ and measured $\mathrm{R}>5 \%$ & $\begin{array}{c}\text { Discrimination between physio- } \\
\text { logical and pathological valve } \\
\text { collapse }\end{array}$ & Yes \\
\hline $\begin{array}{l}\text { Flow at pure turbu- } \\
\text { lence }\end{array}$ & $\begin{array}{l}\text { Mlynski, } \\
\text { Löw }^{19}\end{array}$ & $\begin{array}{l}\text { Flow at exponent } \mathrm{n}=1.8 \text { in the equation } \mathrm{R}=\Delta P / \dot{V}^{\mathrm{n}} \text { as a } \\
\text { function of breathing flow velocity } \\
\qquad n(\dot{V})=\frac{d \ln (\Delta P)}{d \ln (\dot{V})}=\frac{d \Delta P}{d \dot{V}} \cdot \frac{\dot{V}}{\Delta P}\end{array}$ & $\begin{array}{l}\text { Information on transition of la- } \\
\text { minar to turbulent flow behavior } \\
\text { with increasing flow velocity }\end{array}$ & Yes \\
\hline
\end{tabular}

rements can be achieved. As a tool for objective measurement of nasal resistance in nasal provocation tests, AAR was chosen in most studies so far ${ }^{(23)}$.

The correlation between objective and subjective measures on the nasal airway is still a complex issue and many studies did not find a significant correlation ${ }^{(24)}$.

However, the first study following consensus-based standards for the selection of health measurement instruments (COSMIN) concluded, that the Glasgow health status inventory (GHSI), the Glasgow benefit inventory (GBI), PNIF and 4-P AAR all scored appropriately on content validity and reliability and only the GHSI scored well on responsiveness ${ }^{(25)}$.

\section{2) Peak nasal inspiratory flow.}

Peak nasal inspiratory flow can be measured by the Youlten peak flow meter. This is a portable, passive, light and re-usable device, connected to a sterilized face mask.

Described for the first time by Benson in 1971, the correlation between PNIF and both AAR and PEF has been shown already in $1991^{(26)}$. Recent studies have compared PNIF with AAR using statistical correlation tests with the confirmation that a significant correlation exists ${ }^{(27)}$. The reproducibility has been shown in several studies ${ }^{(28-30)}$ and its application in functional rhinosurgery resulted in a diagnostic accuracy of 0.72 at a cut-off of 2000 $\mathrm{ml} / \mathrm{s}(120 \mathrm{~L} / \mathrm{min})^{(31)}$.

Measurements of bilateral PNIF revealed mean values between 
80.8 and $174 \mathrm{~L} / \mathrm{min}$ in different populations, and it does depend not only on sex but also on age, height and lung function ${ }^{(32)}$. Interestingly, in about $90 \%$ of individuals the sum of right-sided PNIF and left-sided PNIF exceeds the value of simultaneous bilateral PNIF; in approximately $10 \%$ of individuals the opposite is true. This finding might correlate with ala nasi insufficiency. Occasionally, either right-sided or left-sided PNIF exceeds the value of simultaneous bilateral PNIF. The only variable that significantly correlates to unilateral PNIF values is height, shown in a modified PNIF value model ${ }^{(33)}$. The PNIF values do not depend on the body mass index ${ }^{(34)}$ as the nasal cavity does not contain fat cells. The influence of lung function and the missing information about nasal valve function and the role of the nasopharynx are essential disadvantages of this method. The PNIF value increases by $0.3 \mathrm{~L} / \mathrm{min}$ per \% increase in FEV1 (\% predicted in spirometry), as published in a study on patients with nasal obstruction and asthma ${ }^{(35)}$.

\section{A. Specifications}

The flow is measured as volume/time and the device should cover a range of at least 30 to $350 \mathrm{~L} / \mathrm{min}$. For the residual volume method, two measurements are taken in the seated or upright position ${ }^{(36)}$ with maximum transnasal inhalation and closed lips, starting from the end of a full expiration. Two measurements are performed each bilaterally and unilaterally, both before and after decongestion, yielding 12 values. The best value from each of the six measurement conditions is recorded. Closure of the contralateral side for unilateral PNIF is performed using a flexible air-tight tape. The seal has to be checked prior to each measurement by blocking the contralateral side and asking the patient to inhale. Blockage of one nasal cavity with cotton wool inside the vestibule is contraindicated because of anatomical changes in the contralateral side and the risk of suffocation.

\section{B. Calibration}

Peak nasal inspiratory meters are currently not calibrated at fixed intervals when in use. This may result in inaccurate values because of material breakdown over time. A PNIF meter must be replaced after three years or after 50,000 measurements. Otherwise, it must be recalibrated by the manufacturer or at a national metrology service every second year with the results and the method of calibration communicated to the hospital administration.

\section{Mask}

For the mask, see the hygienic requirements for rhinomanometry. The device and the mask must be autoclavable. A bacterial filter is not suitable, as it would not allow for comparison with normal peak flow values. Unintentional exhalation or blowing the nose during an attempt to obtain the first PNIF measurement might contaminate not only the mask but also the measuring device.

The impact of mask tightness in males with a beard has not been clarified for PNIF measurement so far.

\section{Recommendation}

Peak nasal inspiratory flow may be used as a fast test and should be supplemented by AR and/or AAR in cases of discrepancy between the symptoms and objective findings. Research about intra- and inter-individual variability is ongoing.

\section{Acoustic rhinometry.}

Acoustic rhinometry is a rapid method of determining morphologic changes in the nasal airways. It is based on the reflection of ultrasound waves, directed into the nasal cavity.

\section{A. Specifications}

Important parameters are the minimal cross-sectional area (mCSA) at different "notches" or spaces and the nasal cavity volume (NCV). The NCV is defined as the space between the opening plane of the device and a parallel plane at a defined distance from the opening plane. For this measurement, either a fixed distance or the distance to the mCSA is applied. Mlynski in 2015 stated, that the MCSA 1 is the narrowest part between 0 and 3 $\mathrm{cm}$ from the external ostium and the mCSA2 between 3 and 5,2 $\mathrm{cm}$ respectively (personal communication). Garcia et al. ${ }^{(39)}$ in 2016 pointed out that AR measurements are affected by several factors: the position of the sound tube and possible leakage at the nostril, the inconsistency in user operation and the overestimation of mCSAs in the posterior nose due to sound leakage into the sinuses. Dynamic changes at the nasal valve during inhalation and exhalation are not represented. When using diagnostic methods designed for morphologic evaluation to obtain functional information, the key question is the relationship between rhinometric parameters and functional airway resistance. A significant correlation between PNIF and AR was found at the mCSA 2 and $m C S A 3$ except for the nasal vestibule space at $0-3 \mathrm{~cm}^{3}$ of the $\mathrm{NCV}{ }^{(37)}$. In one study on responsiveness, the subjective 11-year satisfaction correlated with AR improvement 3 months after septoplasty in pre-decongestion mCSA1, $\mathrm{mCSA} 2$ and $\mathrm{mCSA} 3$, using distances of 0-2.2, 2.21-5.4 and 0-5.4 $\mathrm{cm}$, respectively ${ }^{(38)}$. It could be shown that for low mCSA values a power correlation does exist between MCSA and airway resistance as measured with CFD ${ }^{(39)}$. The law of Hagen-Poiseuille is also valid for irregular cross-sectional areas. The inter-examiner variation with $A R$ has not yet been quantified.

\section{B. Calibration}

The first calibration of the acoustic rhinometer has to be carried out by the producer. Recalibration must be repeated before each measurement. 


\section{Hygiene}

The end pieces of the device must follow hygiene standards and must fit to the configuration of the nostril anatomy on each side. For recalibration, the patient closes the tip of the end piece with a thumb.

\section{Recommendation}

We feel the definition of the MCSA in AR needs further attention and agreement. Either a fixed distance will be defined, which probably will depend on age and ethnic conditions, or the individual distances will be used. Until a common consensus is achieved, it is of importance to describe in detail the chosen definition of the MCSA in each study. The popularity of AR varies widely in different countries. Whereas in Germany AR is used at some research facilities, in Norway the screening diagnostic approach for nasal airway assessment combines AR and PNIF.

\section{Odiosoft-rhino.}

Odiosoft-rhino (OR) is the acoustical analysis of the sound produced by nasal breathing ${ }^{(40)}$. The system consists of a computer program, microphone, a sound card and a computer.

\section{A. Specifications}

The method is an indirect determination/estimation of nasal resistance using a microphone $1 \mathrm{~cm}$ next to the nares. A correlation of OR with the results of AAR and VAS has been shown for frequencies between 2 and $4 \mathrm{kHz}{ }^{(41)}$. The clinical data on the method are limited.

\section{B. Calibration}

A calibration for OR is not specified so far.

\section{Hygiene}

As the microphone is not exposed directly to the nasal airflow, the hygienic prerequisites include a clean microphone and tape, not necessarily sterilised.

\section{Recommendation}

The advantage of the method lies in the hardware which is not expensive and it does not take more than a few minutes to apply the equipment. Studies on the reproducibility have not been published so far and the responsiveness has not been confirmed by other groups.

\section{Optical rhinometry.}

The method is not primarily intended to analyse nasal air flow, but rather uses emission or transmission spectroscopy to evaluate mucosal oedema as indicated by changes in blood flow and light absorption with high reproducibility ${ }^{(42)}$. Intra-individual variability is independent of patient cooperation. Absolute data or norm values are not available for inter-individual variability or comparability; presently, only relative measurements are possible. No patients have to be excluded with this method because it is possible to assess patients with polyps or septum perforation. The test is therefore suitable for nasal provocation tests and has shown promising diagnostic value ${ }^{(43)}$.

\section{24h-measurements.}

The nasal cycle has been studied for more than half a century ${ }^{(44)}$. It remains an open question whether the nasal cycle reflects a central function and/or follows simple gravity conditions ${ }^{(45)}$. Initial data indicate that nasal air flow lateralization relates to the sleep stage with REM phases, measured by EEG ${ }^{(46)}$. Semi-quantitative measurements of nasal breathing have long been a substantial part of polygraphy and polysomnography. The technical principles of these methods are thermistor measurements or pressure measurements; the latter are preferred in sleep medicine ${ }^{(47)}$. Extended information about the role of the nose during sleep can be obtained by using divided cannulas connected to pressure sensors, thus allowing the separate measurement of left and right nasal passages. The role of body position on nasal breathing can be visualized as well in increased nasal resistance in the supine position and side differences in nasal breathing. The form of the recorded breathing waves can themselves hint at a so-called "inspiratory flow limitation". Similar curves are produced in AAR when the nasal valve is active or the soft palate is retracted by nasal breathing.

Particular information about the nose has to be seen generally in the framework of polysomnography and should be supplemented by rhinomanometry and endoscopy in case of pathological findings.

Analysis of long-term measurements must be separated from the influence of physical exertion or body position, which also influences cyclic changes in nasal blood supply.

\section{Computational fluid dynamics.}

The development of CFD methods, which can be included in the daily work of an ENT surgeon, is one of the most promising and challenging tasks for the future of upper and lower airway diagnosis. The analysis is based on CT- or MR-imaging data (48). As such, this method requires patient exposure to radiation, unless CT has been performed for other indications. Casey et al. reported on the middle nasal cavity area as a key space with a high correlation for subjective nasal obstruction measured by VAS and nasal obstruction symptom evaluation score (NOSE) ${ }^{(49)}$. By means of extraction algorithms the three-dimensional surface of the airway, i.e., the interface between air and tissue, is reconstructed from the corresponding CT data ${ }^{(50)}$. This surface consists of a set of triangles forming a watertight volume of the region of interest. It serves as a basis to construct a computational mesh for the simulation. This mesh is necessary to approximately solve the governing equations of fluid mechanics, i.e., 
the Navier-Stokes equations (conservation of mass, momentum, and energy), in their discrete form on computers. LatticeBoltzmann methods (LBM) operating on hierarchical Cartesian meshes ${ }^{(51)}$ have shown to be efficient for the computation of the flow in the nasal cavity ${ }^{(5,48,50,52-54)}$. They allow for effective parallelization, easy boundary treatment, and accurate simulation of respiratory flows. The application of adaptive outflow conditions at geometry outlets placed at the pharynx at inspiration in conjuction with second-order accurate no-slip wall-boundary conditions and Saint-Venant-Wanzel inflow conditions at the nostrils allows an in-solve adjustment of the Reynolds number (50), or in other words, an adaptation of the ratio on inertial to viscous forces. Eitel et al. ${ }^{(50)}$ and Lintermann et al. ${ }^{(5,52,53)}$ have shown detailed studies of the nasal airflow using this method and classify nasal cavities by the total pressure loss, wall-shear stress, heating capability, and heat transfer.

While the feasibility of CFD methods is obvious, the transfer to daily practice is closely related to the development of highperformance small computers and standard programs allowing the use of CFD at a reasonable price.

That is, accuracy, which is defined by the mesh resolution and the simulation and modelling method, comes at a defined computational cost. High resolution simulations are currently only viable by employing high-performance computing (HPC) hardware. For this reason, many approaches follow a model such as The Reynolds-averaging Navier-Stokes (RANS) approach. Such RANS computations are computationally cheaper than directly solving the Navier-Stokes equations without using any modelling approach. However, the error introduced by such models is not easily quantifiable and their application stays questionable since the assumption of turbulent flow, a prerequisite of turbulence models, is not necessarily true for nasal cavity flows. In the end it needs to be stated that to the best of the author's knowledge, no simulation tool has made its way into daily clinical practice so far, at least any which is capable of finding a reasonable balance between computational costs, high accuracy, and user-friendlyness.

Two further tests should be mentioned as suitable for limited indications:

\section{Mirror test.}

This functional assessment is the oldest rhinological test. It is performed with a clean, smooth, preferably cooled surface of at least $5 \times 7 \mathrm{~cm}$, placed under both nostrils to determine the size of the fogged area produced by each nostril during exhalation. Made out of metal, it is autoclavable. The method was extensively described by Hendrik Zwaardemaker from Utrecht and a modified device has been in use since 1901, known as GlatzelSpiegel in Germany. The first documented use of this test appears on a stone wall in southern Italy illustrating its application as a tool to examine a dying woman, dated about 320 BCE. The test is far older than any published medical report on printed paper ${ }^{(55)}$.

The mirror test is a simple, non-invasive (not even touching the patient asleep), non-irradiating, inexpensive and a very fast bedside test, and is recommended for the objective assessment of the nasal passage in newborns and premature babies. The test rules out unilateral or bilateral choanal atresia with a self-evident positive predictive value when combined with a diagnostic nasogastric tube in cases of doubt. Published studies on a diagnostic value are not known. The device's non-invasive character and price per patient are definitely superior to all other nasal function tests for this patient group. One may guess that the test most probably will remain in use for the next 2000 years.

\section{Nasometry.}

The aim of nasometry is the determination of the cause of nasality in speech rather than evaluation of the nasal airway.

Finally, job shift is a reality in the medical profession. Methods such as the mirror test, PNIF, AR, AAR, 24-h measure may altogether be delegated to trained medical assistants. For reasons of effectiveness this is not to avoid to some extent. However, not only the capability but also the possibility to perform these tests on demand should stay in the hands of the rhinologist. The advantage of having the surgeon herself or himself perform the appropriate test is that the process of important verbal and non-verbal communication will continue and that may support shared decision-making in a worldwide constantly increase of multiple possible choices for therapies and surgeries. It was proposed that 'cure' and 'care' are inseparable. Gulbrandsen et al. pointed out that careful curating should foster autonomous capacity, but is not always possible because of lack of familiarity with the information available and exchanged, or with the patient when providers are exchanged. The performance of an objective assessment of the nasal airway should not be underestimated as an element for a reliable relation, especially for the professional care in complex cases ${ }^{(56)}$.

\section{Acknowledgements}

The following experts in different fields took part as faculty members: Aris Giotakis/Greece, Allergology, for the task force "Nasal Provocation Tests" of EAACI. Carlotta Pipolo/Italy; Computational Fluid Dynamics. Detlef Brehmer/Germany, Otorhinolaryngology, Biomedical Engineering. Kaspars Peksis/Latvia, Otorhinolaryngology, for ISCOANA. Maurizio Quadrio/Italy; Comuptational Fluid Dynamics. Rudolfs Viksne, Latvia; medical student. Walter Koch/Austria, Mathematics. Oleg Garyuk/Ukraine, Otorhinolaryngology. The group would like to thank Prof. Indrikis Muiznieks, Rector of the University of Latvia, Riga, for hospitality and support of the conference. 
Partly funded by the Grant Agreement 861510 (IraSME/COIN Programme - Project: Rhinodiagnost). other authors contributed as consultants for mathematics, physics, computational fluid dynamics and medical technology.

\section{Authorship contribution}

$\mathrm{KV}$ and $\mathrm{G} \mathrm{B-H}$, are the authors of this conference report. The

\section{Conflict of interest}

The authors declare no conflicts of interest.

\section{References}

1. Clement PA, Halewyck S, Gordts F, Michel O. Critical evaluation of different objective techniques of nasal airway assessment: a clinical review. Eur Arch Otorhinolaryngol. 2014;271(10):2617-25.

2. Wong EH, Eccles R. Comparison of classic and 4-phase rhinomanometry methods, is there any difference? Rhinology. 2014;52(4):360-5.

3. Fokkens WJ. Blocked noses. Rhinology. 2017:55(2):97-8

4. Gross TF, Peters F. A fluid mechanical interpretation of hysteresis in rhinomanometry. ISRN Otolaryngol. 2011;2011:126520.

5. Lintermann A, Meinke M, Schröder W. Fluid mechanics based classification of the respiratory efficiency of several nasal cavities. Comput Biol Med. 2013;43(11):1833-52.

6. Yerokhin, Nechyporenko A, Babii A, Turuta O. A new intelligence-based approach for rhinomanometric data processing. Proc of International Conference "2016 IEEE 36th International Conference on Electronics and Nanotechnology". 2016:198-201.

7. Chmovzh V, Nechyporenko AS, Garyuk OG. System approach to finding hydrodynamic resistance coefficient of a nasal cavity. Computer science, information technology, automation journal, csita. 2016;4:8-15.

8. Clement PA. Committee report on standardization of rhinomanometry. Rhinology. 1984;22(3):151-5.

9. Clement PA, Gordts F, Standardisation Committee on Objective Assessment of the Nasal Airway IRS, Ers. Consensus report on acoustic rhinometry and rhinomanometry. Rhinology. 2005;43(3):169-79.

10. Eccles R. A guide to practical aspects of measurement of human nasal airflow by rhinomanometry. Rhinology. 2011;49(1):210.

11. Vogt K, Jalowayski AA, Althaus W, Cao C, Han D, Hasse W, et al. 4-PhaseRhinomanometry (4PR)--basics and practice 2010. Rhinol Suppl. 2010(21):1-50.

12. Vogt K, Wernecke KD, Behrbohm H, Gubisch W, Argale M. Four-phase rhinomanometry: a multicentric retrospective analysis of 36,563 clinical measurements. Eur Arch Otorhinolaryngol. 2016;273(5):1185-98.

13. Vogt K, Wernecke KD, Argale M, Kaulina K. Classification of total nasal obstruction in 10,033 cases by 4-phase-rhinomanometry. Rom J Rhinol. 2016:6(23).

14. Broms P. A comprehensive system to describe the resistant properties of the nasal airway. Malmö: University of Malmö; 1980

15. Naito K, Iwata S, Ohoka E, Kondo Y, Takeuchi
M. A comparison of current expressions of nasal patency. Eur Arch Otorhinolaryngol. 1993;250(4):249-52

16. André RF, Vuyk HD, Ahmed A, Graamans K, Nolst Trenite GJ. Correlation between subjective and objective evaluation of the nasal airway. A systematic review of the highest level of evidence. Clin Otolaryngol. 2009;34(6):518-25.

17. Postema CA, Huygen PL, Lecluse RG Wentges RT. The lateralization percentage as a measure of nasal flow asymmetry in active anterior rhinomanometry. Clin Otolaryngol Allied Sci. 1980;5(3):165-70.

18. Chmovzh V, Garyok a, Nechyporenko A Aerodynamics of human nasal cavity. Proc of International Conference "Fluid mechanics in engineering practice". 2015(Ukraine, Kyiv):70-2.

19. Mlynski G, Low J. [Rhinoresistometry--a further development of rhinomanometry]. Laryngorhinootologie. 1993;72(12):608-10.

20. Beule A, Mlynski G, Gogniashvili G Objective rhinometry in pre- and postoperative analysis. In: Lalwani, Pfister, editors. Recent Advances in OtolaryngologyHead and Neck Surgery. Volume 6: Jaypee Brothers Limited; 2017.

21. Gogniashvilli G, Steinmeier E, Mlynski G Beule AG. Physiologic and pathologic septal deviations: subjective and objective functional rhinologic findings. Rhinology. 2011;49(1):24-9.

22. Eichler J. Einführung in die Technik der Rhinomanometrie.: Quintessenz-Verlag Berlin-Chicago-London-Sao-Paulo-Tokio; 1988

23. Hamizan AW, Rimmer J, Alvarado R, Sewel WA, Kalish L, Sacks R, et al. Positive allergen reaction in allergic and nonallergic rhinitis: a systematic review. Int Forum Allergy Rhinol. 2017

24. Nivatvongs W, Earnshaw J, Roberts D Hopkins C. Re: Correlation between subjective and objective evaluation of the nasal airway. A systematic review of the highest level of evidence. Clin Otolaryngol. 2011;36(2):181-2.

25. van Egmond $M$, van Heerbeek $N$, Ter Haar ELM, Rovers MM. Clinimetric properties of the Glasgow Health Status Inventory, Glasgow Benefit Inventory, Peak Nasal Inspiratory Flow, and 4-Phase Rhinomanometry in adults with nasal obstruction. Rhinology. 2017;55(2):126-34.

26. Jones AS, Viani L, Phillips D, Charters P. The objective assessment of nasal patency. Clin Otolaryngol Allied Sci. 1991;16(2):206-11.

27. Ottaviano G, Lund VJ, Nardello E, Scarpa B, Frasson G, Staffieri A, et al. Comparison between unilateral PNIF and rhinomanometry in healthy and obstructed noses. Rhinology. 2014;52(1):25-30.

28. Klossek JM, Lebreton JP, Delagranda A, Dufour X. PNIF measurement in a healthy French population. A prospective study about 234 patients. Rhinology. 2009;47(4):389-92

29. Starling-Schwanz R, Peake HL, Salome CM, Toelle BG, Ng KW, Marks GB, et al. Repeatability of peak nasal inspiratory flow measurements and utility for assessing the severity of rhinitis. Allergy. 2005;60(6):795800

30. Silkoff PE, Chakravorty S, Chapnik J, Cole P, Zamel N. Reproducibility of acoustic rhinometry and rhinomanometry in normal subjects. Am J Rhinol. 1999;13(2):131-5.

31. Bermuller $C$, Kirsche $H$, Rettinger $G$, Riechelmann $H$. Diagnostic accuracy of peak nasal inspiratory flow and rhinomanometry in functional rhinosurgery. Laryngoscope. 2008;118(4):605-10.

32. Ottaviano G, Fokkens WJ. Measurements of nasal airflow and patency: a critical review with emphasis on the use of peak nasal inspiratory flow in daily practice. Allergy. 2016;71:162-74

33. Ottaviano G, Scadding GK, Scarpa B, Accordi D, Staffieri A, Lund VJ. Unilateral peak nasal inspiratory flow, normal values in adult population. Rhinology. 2012;50(4):386-92.

34. Demir MG, Ylmaz HB. The Relation Between Body Mass Index and Nasal Airflow. J Craniofac Surg. 2015;26(4):e295-7.

35. Thorstensen WM, Sue-Chu M, Bugten V. Cvancarova M, Steinsvag SK. The determining factors of peak nasal inspiratory flow and perception of nasal airflow in asthmatics. Rhinology. 2014;52(4):348-54.

36. Ottaviano G, Scadding GK, lacono V, Scarpa B, Martini A, Lund VJ. Peak nasal inspiratory flow and peak expiratory flow. Upright and sitting values in an adult population. Rhinology. 2016;54(2):160-3

37. Kjaergaard T, Cvancarova M, Steinsvag SK. Relation of nasal air flow to nasal cavity dimensions. Arch Otolaryngol Head Neck Surg. 2009;135(6):565-70.

38. Toyserkani NM, Frisch T, Von Buchwald C. Postoperative improvement in acoustic rhinometry measurements after septoplasty correlates with long-term satisfaction. Rhinology. 2013;51(2):171-5.

39. Garcia GJ, Hariri BM, Patel RG, Rhee JS. The relationship between nasal resistance to airflow and the airspace minimal cross-sectional area. J Biomech. 2016;49(9):1670-8.

40. Tahamiler R, Alimoglu Y, Canakcioglu S. Comparison of Odiosoft-Rhino and rhi- 
nomanometry in evaluation of nasal patency. Rhinology. 2011;49(1):41-5.

41. Tahamiler R, Alimoglu Y, Canakcioglu S The contribution of erectile elements to nasal patency: an examination with nasa sound analysis. Int Forum Allergy Rhinol. 2015;5(1):66-70

42. Wustenberg EG, Zahnert T, Huttenbrink KB, Hummel T. Comparison of optical rhinometry and active anterior rhinomanometry using nasal provocation testing. Arch Otolaryngol Head Neck Surg. 2007;133(4):344-9.

43. Krzych-Falta E, Furmanczyk K, Samolinski B. Specificity and sensitivity assessment of selected nasal provocation testing techniques. Postepy Dermatol Alergol. 2016;33(6):464-8.

44. Stoksted P. Rhinometric measurements for determination of the nasal cycle. Acta Otolaryngol Suppl. 1953;109:159-75.

45. Williams M, Eccles R. A model for the central control of airflow patterns within the human nasal cycle. J Laryngol Otol. 2016;130(1):82-8.

46. Frye RE, Rosin DF, Morrison AR, LeonSarmiento FE, Doty RL. Modulation of the ultradian human nasal cycle by sleep stage and body position. Arq Neuropsiquiatr. 2017;75(1):9-14

47. Rohrmeier C, Schittek S, Ettl T, Herzog M, Kuehnel TS. The nasal cycle during wakefulness and sleep and its relation to body position. Laryngoscope. 2014;124(6):1492-7.
48. Achilles N, Pasch N, Lintermann A, Schröder W, Mösges R. Computational fluid dynamics: a suitable assessment tool of demonstrating the antiobstructive effect of drugs in the therapy of allergic rhinitis. Acta Otorhinolaryngol Ital. 2013:33:36-42.

49. Casey KP, Borojeni AA, Koenig LJ, Rhee JS, Garcia GJ. Correlation between Subjective Nasal Patency and Intranasal Airflow Distribution. Otolaryngol Head Neck Surg. 2017;156(4):741-50

50. Eitel G, Freitas RK, Lintermann A, Meinke M, Schröder W. Numerical Simulation of Nasal Cavity Flow Based on a Lattice-Boltzmann Method. New Results Numer Exp Fluid Mech VII, Notes on Numerical Fluid Mechanics and Multidisciplinary Design. 2010;112:513-20.

51. Lintermann A, Schlimpert S, Grimmen JH, Günther C, Meinke M, Schröder W. Massively parallel grid generation on HPC systems. Comput Methods Appl Mech Eng. 2013;277:131-53.

52. Lintermann A, Eitel-Amor G, Meinke M Schröder W. Lattice-Boltzmann Solutions with Local Grid Refinement for Nasal Cavity Flows. New Results Numer Exp Fluid Mech VIII, Notes on Numerical Fluid Mechanics and Multidisciplinary Design. 2013;121:58390

53. Lintermann A, Meinke M, Schröder W Investigations of the Inspiration and Heating Capability of the Human Nasal Cavity Based on a Lattice-Boltzmann
Method. Proc ECCOMAS Themat Int Conf Simul Model Biol Flows (SIMBIO) Brussels, Belgium. 2011.

54. Hörschler I, Schröder W, Meinke M. On the assumption of steadiness of nasal cavity flow. J Biomech. 2010;43(6):1081-5.

55. Pirsing W. Test Using Vapourated Expired Nasal Breathing in Medicine 100 Years ago and in Paestum 2300 Years ago. Laryngorhinootologie. 2014;93(11):739-45.

56. Gulbrandsen P, Clayman ML, Beach MC, Han PK, Boss EF, Ofstad EH, et al. Shared decision-making as an existential journey: Aiming for restored autonomous capacity. Patient Educ Couns. 2016;99(9):1505-10.

57. Bergmane A. Investigations about performance and work of nasal breathing. Diploma work. University of Latvia 2017.

Prof. Dr. Dr. Klaus Vogt

Schwarzer Weg 3 B

18292 Krakow am See

Germany

Tel.: +49 38457507647

Fax: +49 38457507648

alt. +4763876312

E-mail: rhinovogt@t-online.de 